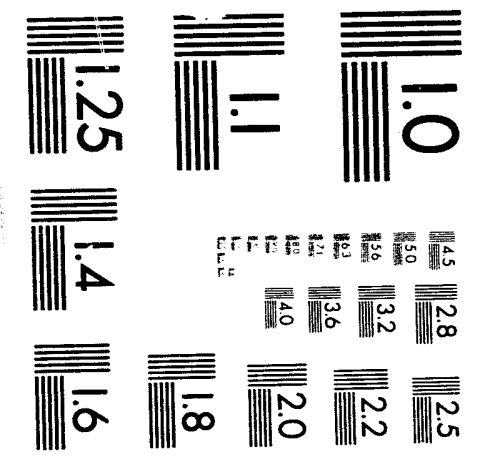



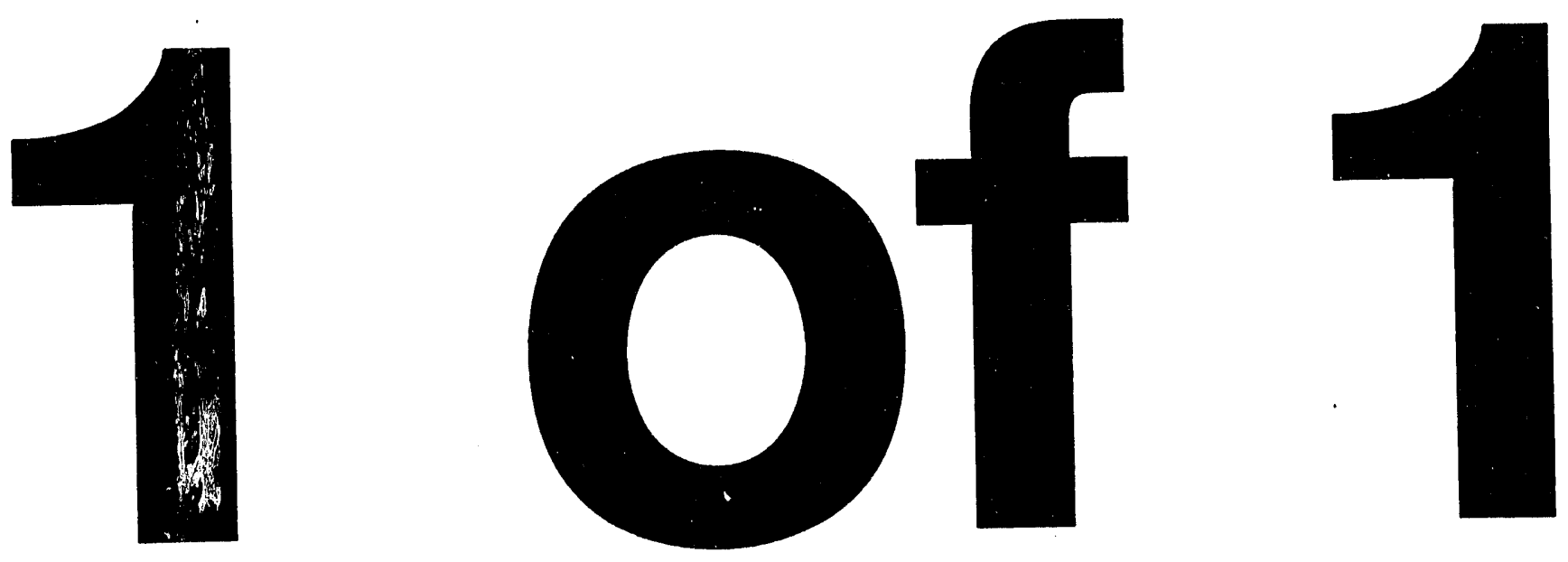


\title{
INSTALLATION AND \\ INITIAL OPERATION OF \\ THE DIII-D ADVANCED DIVERTOR \\ CRYOCONDENSATION PUMP
}

\author{
by \\ J.P. SMITH, K.M. SCHAUBEL, C.B. BAXI, \\ G.L. CAMPBELL, A.W. HYATT, G.J. LAUGHON, \\ M.A. MAHDAVI, E.E. REIS, M.J. SCHAFFER, \\ D.L. SEVIER, R.D. STAMBAUGH, and M.M. MENON*
}

This is a preprint of a paper to be presented at the 15th IEEE Symposium on Fusion Engineering, October 11-15, 1993, Cape Cod, Massachusetts, and to be printed in the Proceedings.

\author{
Work supported by \\ U.S. Department of Energy \\ Contract Nos. DE-AC03-39ER51114 \\ and DE-AC05-840R21400 \\ *Oak Ridge National Laboratory \\ GENERAL ATOMICS PROJECT 3466 \\ OCTOBER 1993
}

\section{GENERAL ATOMICS MASTER}




\title{
INSTALLATION AND INITIAL OPERATION OF THE DIII-D ADVANCED DIVERTOR CRYOCONDENSATION PUMP
}

\author{
J.P. Smith, K.M. Schaubel, C.B. Baxi, G.L. Campbell, A.W. Hyatt, G.J. Laughon, \\ M.A. Mahdavi, E.E. Reis, M.J. Schaffer, D.L. Sevier, and R.D. Stambaugh \\ General Atomics \\ P.0. Box 85608 , San Diego, California 92186-9784 \\ M.M. Menon \\ Oak Ridge National Laboratory \\ Oak Ridge, Tennessee 37831
}

\begin{abstract}
Phase two of a divertor cryocondensation pump, the Advanced Divertor Program, is now installed in the DIII-D tokamak at General Atomics and complements the phase one biasable ring electrode. The installation consists of a $10 \mathrm{~m}$ long cryocondensation pump located in the divertor baffle chamber to study plasma density control by pumping of the divertor. The design is a toroidally electrically continuous liquid helium-cooled panel with $1 \mathrm{~m}^{2}$ of pumping surface. The helium panel is single point grounded to the nitrogen shield to minimize eddy currents. The nitrogen shield is toroidally continuous and grounded to the vacuum vessel in 24 locations to prevent voltage potentials from building up between the pump and vacuum vessel wall. $A$ radiation/particle shield surrounds the nitrogen-cooled surface to minimize the heat load and prevent water molecules condensed on the nitrogen surface from being released by impact of energetic particles. Large currents ( $>5000$ A) are driven in the helium and nitrogen panels during ohmic coil ramp up and during disruptions. The pump is designed to accommodate both the thermal and mechanical loads due to these currents. A feedthrough for the cryogens allows for both radial and vertical motion of the pump with respect to the vacuum vessel. Thermal performance measured on a prototype verified the analytical model and thermal design of the pump. Characterization tests of the installed pump show the pumping speed in deuterium is $42,000 \mathrm{\ell} / \mathrm{sec}$ for a pressure of $5 \mathrm{mT}$ Torr. Induction heating of the pump (at $300 \mathrm{~W}$ ) resulted in no degradation of pumping speed. Plasma operations with the cryopump show a $60 \%$ lower density in $\mathrm{H}$-mode.
\end{abstract}

\section{INTRODUCTION}

The Advanced Divertor Program (ADF) for DIII-D, a mid-sized tokamak designed, built and now operated by General Atomics, was launched in 1989 as an integrated scientific and technology program with the experimental objectives to study proposed concepts for density control, enhancement of plasma performance, and current drive.

The first phase of the ADP was the installation of a toroidally continuous ring electrode biasable to $600 \mathrm{~V}$ with $20 \mathrm{kA}$, and a toroidal gas baffle creating a pumping plenum in the lower outer corner of the vacuum chamber (Fig. 1). Resi'ts for the first phase were good with biasing and particle entrapment demonstrated [1]. Large gas pressures were built up under the gas baffle demonstrating particles being collected and not recycled back into the core plasma. Biasing could increase or decrease this pressure depending on polarity.

A toroidally continuous cryocondensation pump was recently installed in the DIII-D tokamak. This pump, the first divertor cryopump to be operated in a tokamak, is located under the toroidal gas baffle and provides active pumping of the divertor. The pumping is achieved by cryocondensation of particles on a $4.6 \mathrm{~K}$ liquid helium cooled surface. Particles condensed on the helium cooled surface are prevented from recycling back into the plasma during the experiment. The pump enables the study of plasma exhaust and density control by divertor pumping and is expected to provide low density plasmas for if current drive. The pump also provides the ability to study the independent scaling of electron density and plasma current.

\section{DESIGN}

A cross-section of the pump and its location in the pumping plenum is shown in Fig. 1. The pump is comprised of a series of concentric Inconel 625 tubes cut and assembled together. The $1 \mathrm{~m}^{2}$ pumping surface consists of a $10 \mathrm{~m}$-long, $25 \mathrm{~mm}$-diameter Inconel 625 tube with liquid helium flowing inside. Surrounding the pumping surface are liquid nitrogen cooled shields limiting the steady state heat load on the helium system to less than $10 \mathrm{~W}$. Surrounding the nitrogen cooled surfaces is a radiation/particle shield to prevent energetic divertor particles from releasing water previously condensed on liquid nitrogen surfaces. The aperture to the pump is created by cutting windows in the radiation/ particle and outer nitrogen shields. The inner nitrogen shell shields the helium tube from incoming energetic particles. All particles entering the pump must bounce

Mamuscript received October 12, 1993. This is a report of work sponsored by the U.S. Department of Energy under Contract Nos. DE-AC03-89ER51114 and DE-AC05-84OR21400. 


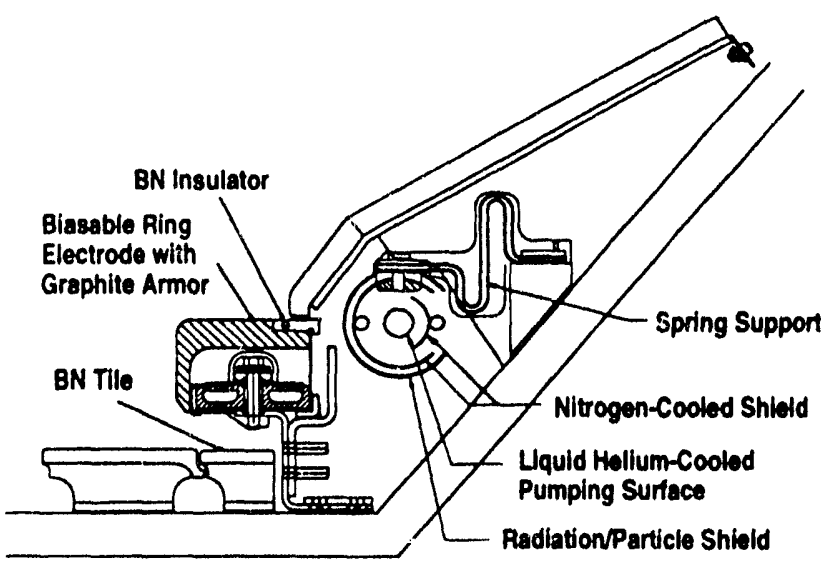

FrG. 1. Advanced divertce hardware in outer lower corner of DIII-D vacuum vessel.

off a nitrogen cooled surface at least twice before striking the helium surface. The nitrogen cooled surfaces have a high emissivity to absorb a large fraction of the incoming thermal radiation. The helium and nitrogen systems are electrically connected only at the feed through flange to prevent eddy current heating and additional loads on the pump.

A toroidally continuous geometry for both the helium and nitrogen systems was chosen to limit the voltage potentials and possible breakdown in the plasma filled pumping plenum between the pump and the vacuum vessel wall. The liquid helium tube is toroidally continuous to react the radial loads created during plasma disruption. The current driven in the tube as a result of the one-turn voltage applied to the plasma and also during plasma disruptions create joule heating of the helium tube. The effect of this resistive heat load on the liquid helium flow stability was evaluated by testing on a mockup of the actual helium tube geometry. The current driven in the tube during a disruption inputs additional joules to the helium circuit. Joule heating caused by a disruption is not a concern beaust the disruption terminals, the shots, and the pump will be regulated by the glow discharge cleaning. Large forces on the helium tube and nitrogen shells do result from the currents driven in the tube [2]. Vertical loads on the helium line are reacted by low heat leak spring supports located every 15 degrees. These springs also help attenuate the impulse load of the disruption. The nitrogen shell is also a toroidally continuous tube reacting radial loads in hoop stress. Outside of the nitrogen shell is a radiation/particle shell in 24 segments to limit the radiation heat load on the nitrogen panel and to prevent water condensed on the surface from being desorbed by energetic particles. These shells are each single point grounded to the nitrogen panel to minimize eddy current loops.

The pump is supported to the vessel via flexible supports attached to the nitrogen shell. The support is designed to allow for the thermal contraction of the system at cryogenic temperatures and for low heat leak while the vessel is at $25^{\circ} \mathrm{C}$. The natural frequency of the support system in the vertical direction is designed to have no resonance near the $21 \mathrm{~Hz}$ natural frequency of the vessel wall. The supports are also designed to attenuate the impulse loads induced on the pump components during disruptions.

Flow of the liquid helium inside the $25 \mathrm{~mm}$ Inconel tube is annular flow around a $19 \mathrm{~mm}$-diameter core made of a thin walled tube $(0.25 \mathrm{~mm})$. The flow channel was designed to achieve a flow velocity of $0.5 \mathrm{~m} / \mathrm{sec}$ and maintain a large thermal capacity. The inner tube has slots to allow liquid helium to fill the center of the core. Flow restrictors are placed every $75 \mathrm{~mm}$ in the inner tube to minimize the amount of flow through the center to less than $10 \%$. Extensive testing of different flow configurations led to the choice of this annular flow design based on its heat load capability [3].

All the cryogens flow into and exit out the vacuum vessel through a single feed through port. An inlet and exit line for helium and nitrogen pass through a conflat flange, but remain electrically isolated from the vacuum vessel to minimize eddy or disruption induced currents from flowing across the toroidal field in the feed lines. The four feed lines are surrounded by a liquid nitrogen cooled shield to minimize the radiative heat load on them from the vessel wall. The four feed lines were also designed to accommodate the change in radius of the pump relative to the vessel wall $(5 \mathrm{~mm})$. A dynamic analysis of the feed lines was completed for disruption induced loads in the pump and vessel. The feed lines allow the pump to oscillate vertically during a disruption at a different frequency than the vessel wall. The disruption induced loads on the feed tubes were also included in the analysis [4]. An ex-vessel cryogenic support system was designed to support the operation of the pump and is described in [5].

\section{MANUFACTURE, ASSEMBLY, AND INSTALLATION}

The pump was manufactured by rolling Inconel tubing to the appropriate major radius and annealing. The nitrogen shells and tubes were annealed in air to give an oxide layer with a high emissivity. Laser cutting was used to machine the windows and other features into the tubes. This method was chosen to minimize distortion and residual stresses of the parts during machining.

The helium pumping surface was polished by hand with progressively finer abrasives to at least $0.1 \mu \mathrm{m}$ to enhance the reflectivity and minimize the heat load on the surface. The liquid nitrogen flow tubes were attached to the nitrogen shells using a series of $25 \mathrm{~mm}$-long plug welds spaced every $50 \mathrm{~mm}$. This weld provides both the structural and thermal connection from the tube to the shield. 
The outer nitrogen shell has copper stripes, flame sprayed on the outside, to enhance azimuthal thermal conductance (Fig. 2). This is needed to keep a maximum surface temperature of $110 \mathrm{~K}$ on the nitrogen shell and to reduce temperature differences and stresses during cooldown and warmup transients. The stripes are $25 \mathrm{~mm}$ wide, spaced every $50 \mathrm{~mm}$ along the length of the pump. The stripes coincide with the plug welds to maximize the thermal conductance. The copper is not toroidally continuous to keep the electrical resistance high to reduce the electromagnetic forces on the pump.

The pump was pre-assembled on a tooling plate in 120 degree sectors. Each sector was thermally shocked to liquid nitrogen temperatures and leak checked before being installed in the DIII-D tokamak. A practice installation was performed in the staging area to verify assembly techniques and demonstrate access to all welds. The three pump sector assemblies were then brought into the vessel, welded together, thermally shocked again, and leak checked. The pump installed behind the bias ring is shown in Fig. 3.

\section{OPERATION OF PUMP}

Initial cooldown tests of the pump were successful. The liquid nitrogen components cooled down in less than $30 \mathrm{~min}$ from $300 \mathrm{~K}$, and the helium surface chilled down from 300 to $4.6 \mathrm{~K}$ in $4.5 \mathrm{~min}$ once the nitrogen shields were cooled. The helium panel was repeatedly cooled and warmed up without problems.

Startup of the machine with the installed cryopump was routine. After initial pump down, DIII-D was inductively baked to $400^{\circ} \mathrm{C}$. Baking of the pump occurred along with the vacuum vessel by driving currents in the toroidally continuous pump. The temperature of the

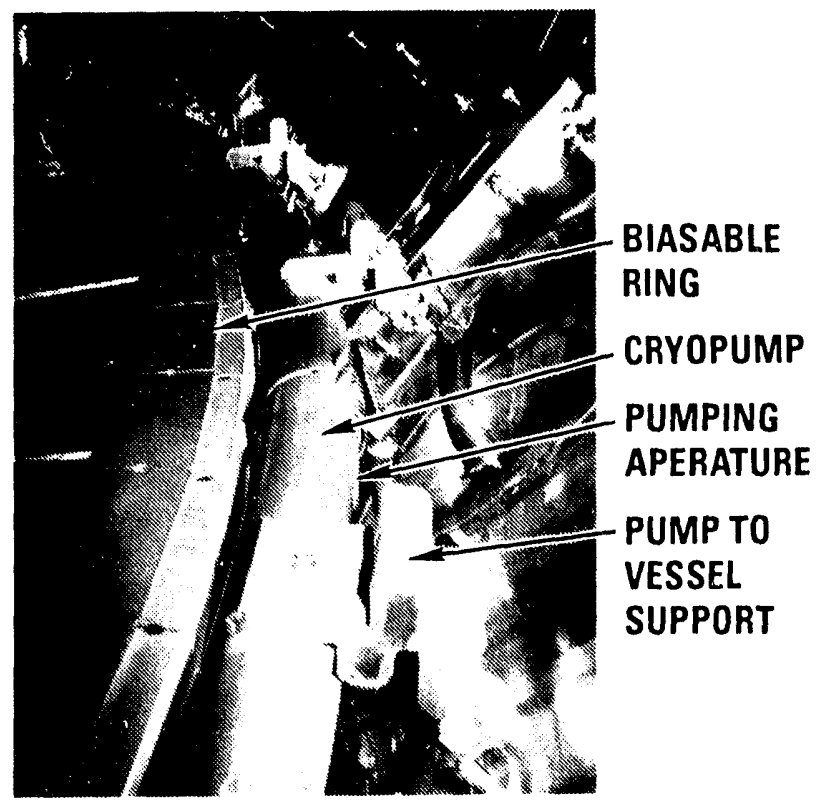

FIg. 2. Outer nitrogen shell with copper stripes to enhance azimuthal thermal conductivity.

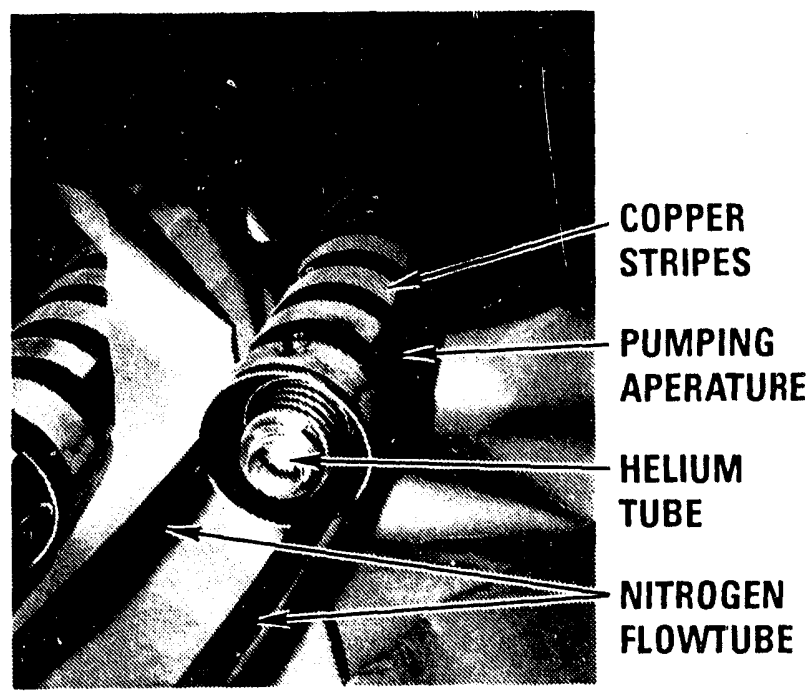

Fig. 3. Pump installed in DIII-D behind biasable ring.

pump rose faster than the vessel temperature due to the lower electrical resistance and mass of the system. The critical limitation for the pump was to not exceed a temperature difference of $230^{\circ} \mathrm{C}$ between the vessel and pump.

A series of tests was performed to measure the pumping speed and thermal capability of the pump. The pumping speed was measured for deuterium by cooling the pump and injecting into the vessel a known quantity of deuterium and measuring the rate of pressure decay. Using this method, the measured pumping speed was $42,000 \ell / \mathrm{sec}$ at a pressure of $5 \mathrm{~m}$ Torr [6]. Pumping analysis of the cryopump using the DEGAS code resulted in a design pumping speed of $50,000 \ell / \mathrm{sec}$ assuming axisymmetry of the pump aperture and vessel wall [7]. The approximate length of the pump with reduced or no aperture to the helium surface is $3 \mathrm{~m}$ or $30 \%$ of the pump length. This reduces the design pumping speed accordingly to $35,000 \ell / \mathrm{sec}$. In addition, the vessel wall is not axisymmetric either. It has ports and the reflection of particles is not the same as predicted in the DEGAS calculations.

The thermal capability of the pump was tested by inducing currents in the helium line using the ohmic heating coils. Using this method, flow stability of the helium was maintained for resistive heat loads of greater than $300 \mathrm{~W}$ for $8 \mathrm{sec}$. During this test, the pressure in the vessel was monitored to determine if the pumping surface warmed up. No pressure spikes were detected. In addition, the flow stability of the liquid helium was carefully monitored watching for pressure instabilities created by an excessive heat load.

During plasma operations, the pump is regenerated between shots. This is done for two reasons. The first is to minimize frost build up of deuterium and other condensables on the cold surface. The second is helium glow 
discharge cleaning used between shots on DIII-D creates a large conductive heat load to the liquid helium pumping surface and would render the helium flow unstable. The liquid helium flow is shut off between shots and the panel warmed up to between 10 and $20 \mathrm{~K}$, regenerating the pumping surface. The helium panel cools down in less than $5 \mathrm{~min}$ to be ready for the next plasma shot. The operation of the pump is computer controlled and interlocked into the DIII-D control computer. The machine has been routinely operated since the installation of the pump including several fast $2 \mathrm{MA}$ disruptions. The resulting large electromagnetic loads created no problems for the pump. No arcing was detected during their disruptions.

In the run campaign prior to pump installation, static pressure under the toroidal gas baffle has been measured to be as great as 14 mTorr. With active pumping of the divertor, the baftle pressure is typically a factor of four lower. Initial plasma operations with the cryopump reveal positive results with respect to density control during $\mathrm{H}$-mode shots. On comparable $1 \mathrm{MA} \mathrm{H}$-mode shots, the density during pumped shots is $60 \%$ of a similar shot without pumping (Fig. 4). The electron temperature
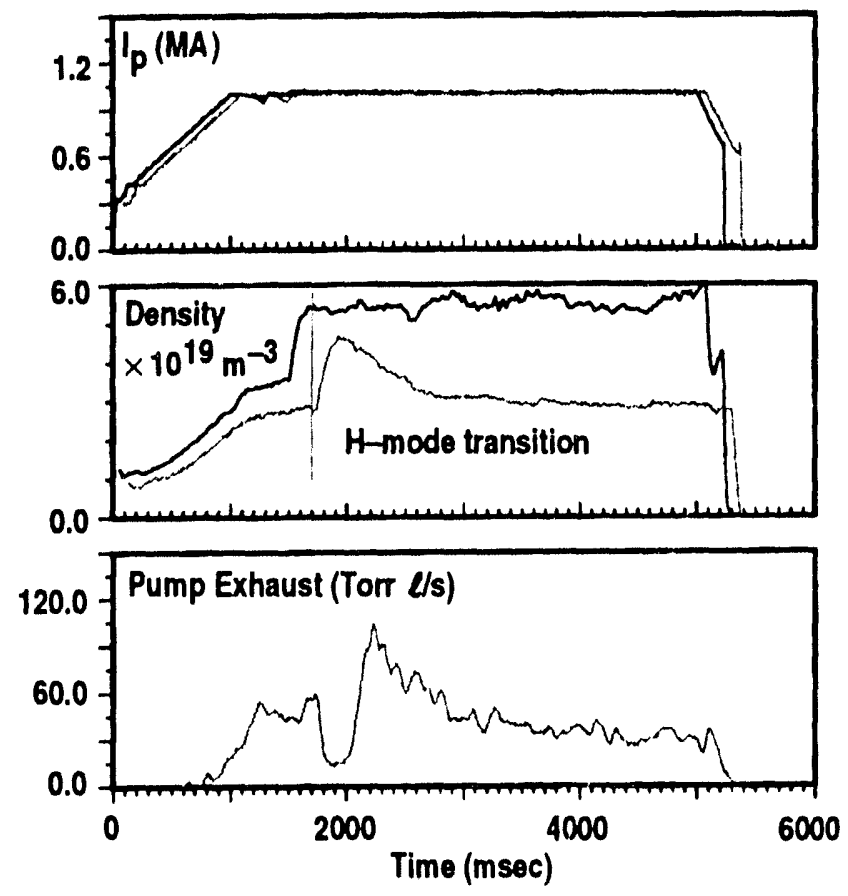

Fig. 4. Comparison of two shcts with and without divertor pumping: (a) plasma current, (b) line average electron density, and (c) pump exhaust (calculated). rises roughly proportionally to the electron density drop [8-9].

For bakeout after cold operation, the pump must first be warmed by back filling the vessel to $10 \mathrm{~m}$ Torr of helium for approximately one hour to boil off the liquid cryogens and initiate the warming of the cold surfaces. The pump can then be baked along with the rest of the machine.

In conclusion, operation of the cryopump has been successful. It is the first cryopump operated in a tokamak for pumping of a divertor and has operated flawlessly. Initial conditioning of the pump and vacuum vessel was completed by baking to $350^{\circ} \mathrm{C}$. The pump has operated near its design parameters. Most important, the pump has demonstrated the ability to control the density in $\mathrm{H}$-mode plasmas.

\section{REFERENCES}

[1] M.A. Mahdavi, M.J. Schaffer, P. Anderson, C. Baxi, J.N. Brooks, D. Buchenauer, et al., "Divertor baffling and biasing experiments on DIII-D," in Plasme Physics and Controlled Nuclear Fusion Reseanch, vol. 1 (Proc. 13th Int. Conf., Washington, 1990) IAEA, Vienna, 1991, p. 335-343.

[2] J.P. Smith, C. Baxi, E. Reis, and L. Sevier, "A cryocondensation pump for the DIII-D advanced divertor program," in Proc. 10th Topical Meeting on the Technology of Fusion Energy, Boston, 1992.

[3] G.J. Laughon, C.B. Baxi, G.L. Campbell, M.A. Mahdavi, C.C. Makariou, J.P. Smith, et al., "Two-phase liquid helium flow testing to simulate operation of a cryocondensation pump in the DIII-D tokamak," unpublished.

[4] E. Reis, I. Almajan, C.B. Baxi, M.M. Menon, M.J. Schaffer, D.L. Sevier, and J.P. Smith, "Design and analysis of the cryopump for the DIII-D advanced divertor," in Proc. 17th Symp. on Fusion Technology, Rome, 1992.

[b] K.M. Schaubel, C.B. Baxi, G.L. Campbell, A.M. Gootgeld, A.R. Langhorn, G.J. Laughon, et. al., "Design of the advanced divertor pump cryogenic system for DIII-D," in Proc. 14th IEEE Symp, on Fusion Engineering, San Diego, 1991.

[6] M.M. Menon, C.B. Baxi, G.L. Campbell, K.L. Holtrop, A.W. Hyatt, G.J. Laughon et al., "Performance characteristics of the DIII-D advanced divertor cryopump," this symposium.

[7] M.M. Menon, P.M. Anderson, C.B. Baxi, A. Langhorn, J.L. Luxon, M.A. Mahdavi, et al., "Particle exhaust scheme using an in-vessel cryocondensation pump in the advanced divertor configuration of the DIII-D tokamak," Fusion Technol., vol. 22, pp. 356, 1992.

[8] M.A. Mahdavi, M.J. Schaffer, S.L. Allen, P. M. Anderson, M.E. Austin, C.B. Baxi, et al., "Active density control in DIII-D Hmode plasmas," in Proc. 20th EPS Conf. on Controlled Fusion and Plasma Physics, Lisbon, 1993, in press.

[9] M.J. Schaffer, S.L. Allen, N.H. Brooks, D. Buchensuer, R.B. Campbell, J.W. Cuthbertson, et al., "Results from the DIII-D Advanced Divertor Program," in Proc. 9th LAEA Workshop on Stellarators, Garching, 1993, in preas. 

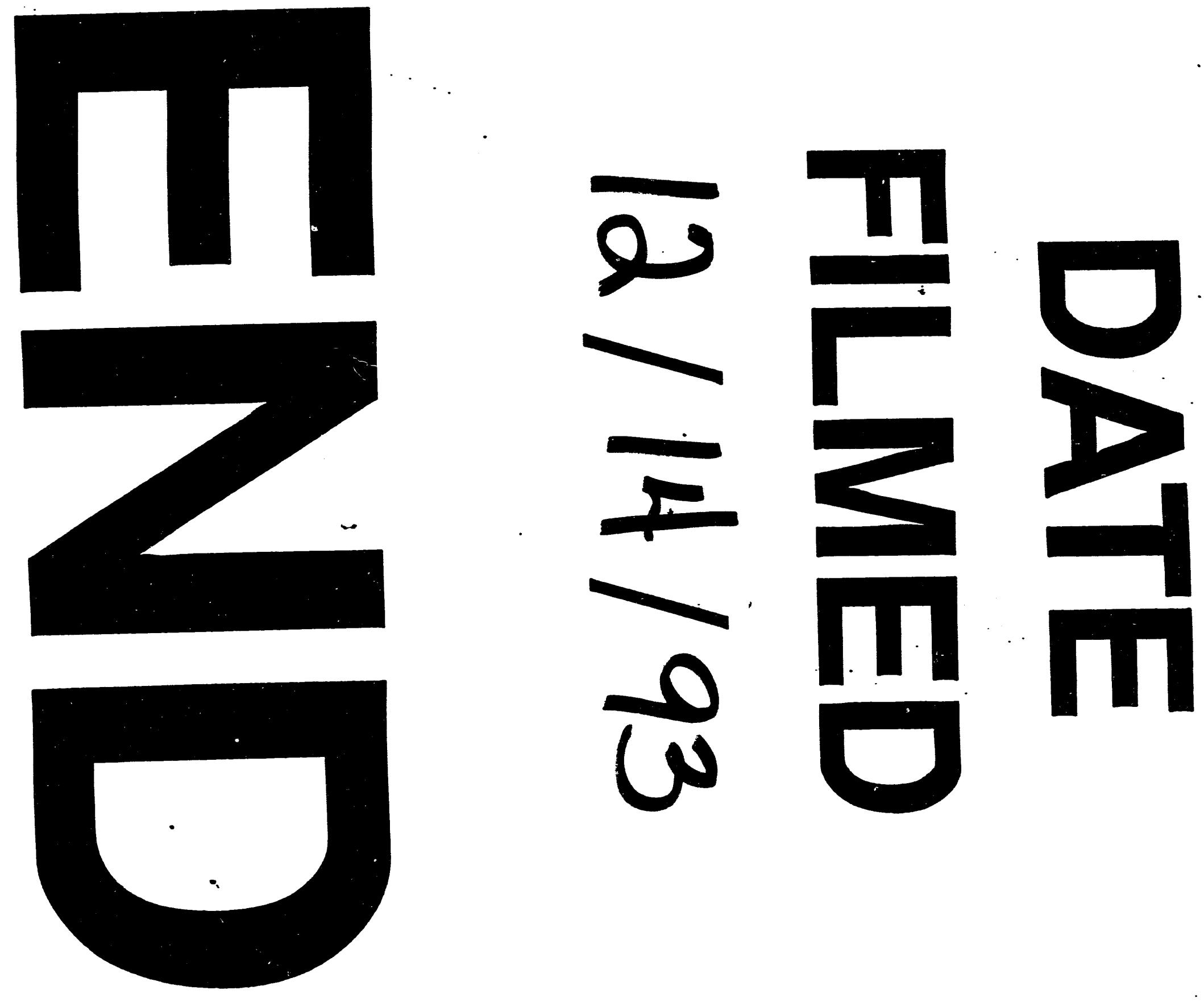


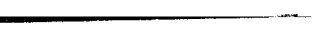

